\title{
Experimental Study the Effect of Tool Geometry on Dimensional Accuracy in Single Point Incremental Forming (SPIF) Process
}

\author{
Aqeel Sabree Bedan \\ Dep. of Production Engineering and Metallurgy \\ University of Technology, Baghdad, IRAQ \\ 70061@uotechnology.edu.iq
}

\author{
Halah Ali Habeeb \\ Dep. of Production Engineering and Metallurgy \\ University of Technology, Baghdad, IRAQ \\ eng_hala.ali60@yahoo.com
}

Received: 09- Oct.-2017

Revised: 05-Nov.-2017 Accepted: 18- Dec.-2017

\begin{abstract}
http://doi.org/10.29194/NJES21010108
\end{abstract}
\begin{abstract}
Incremental forming is a flexible sheet metal forming process which performed by utilizes simple tools to locally deform a sheet of metal along a predefined tool path without using of dies. One limitations of single point incremental forming (SPIF) process is the error occur between the CAD design and the product profile. This work presents the single point incremental forming process for produced pyramid geometry and studied the effect of tool geometry, tool diameter, wall angle, and spindle speed on the dimensional accuracy. Three geometries of forming tools were used in experimental work: ball end tool, hemispherical tool, and flat with round corner tool. The sheet material used was pure Aluminum (Al 1050) with thickness of (0.9 $\mathrm{mm})$. The experimental tests in this work were done on the computer numerical control (CNC) vertical milling machine. The products dimensions were measured by utilized the dimensional sensor measuring instrument. The extracted results from the single point incremental forming process indicated the best acceptance between the CAD profile and product profile was found with the ball end tool and diameter of (10 $\mathrm{mm})$, wall angle $\left(50^{\circ}\right)$ and the rotational speed of the tool was $(800 \mathrm{rpm})$.
\end{abstract}

Keywords: SPIF process, CNC milling machine, Dimensional accuracy.

\section{Introduction}

Single Point Incremental Forming (SPIF) process has been produced from sheet metal content spinning, sheet metal shear moving and hammering with included CNC system to control the forming tool motion [1]. SPIF is a comparatively recent bed sheet forming process which enables forming of complicated shapes without specific dies utilizing only a single point tool and a standard three-axis CNC machine [2].

SPIF is a progressive and adaptable bed sheet metal-forming technology that utilizations layered manufacturing basis. That changes the part geometry data for a several parameters of 2D layers, and after that the plastic-local deformation is done layer-by-layer over the CNC machine motions of the simple forming tool to manufacture products with complicated shapes as demonstrated in figure (1) [3, 4]. The main limitations of single point incremental forming process are bending of sheet occurs as a result of tool drawing effect; it can be minimized by using a backing plate, but this increases the costs of the operation, geometrical errors occur such as spring back, pillow effect and sheet bending as shown in figure (2) [5].

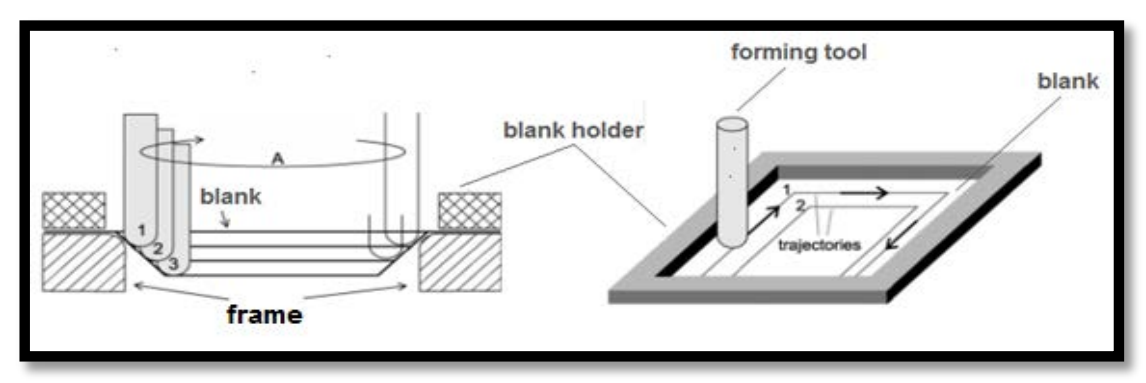

Figure 1: Representation of SPIF process [3]. 


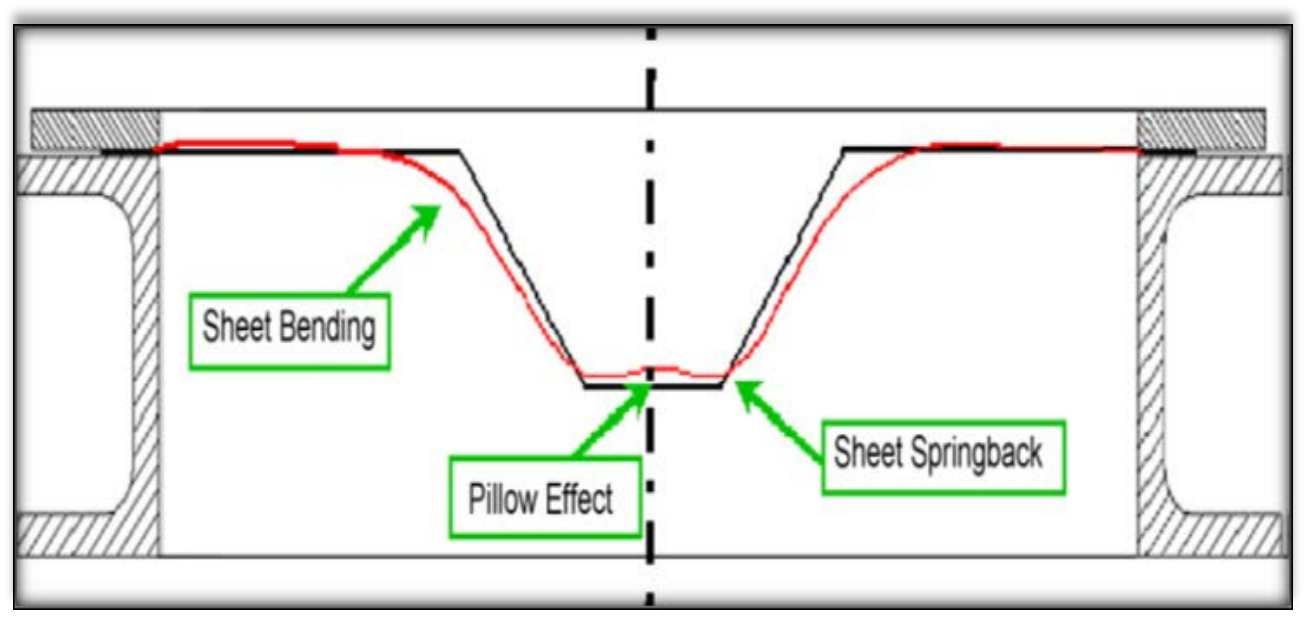

Figure 2: Geometrical errors during the SPIF process [6].

Many researchers studied the effect of SPIF process parameters on the dimensional accuracy; William L. Edwards et al [7] studied the influence of the SPIF processes parameters on the spring back of the polycarbonate sheet. The processes parameters were contained heat, feed rate, spindle speed, and vertical step. The results were indicated the increase in the feed rate and the spindle speed lead to decrease in spring back. And when applied the heat, the spring back was reduced. Halil Bayram and Nurullah Sinan Köksal [8] presented the forming of AA2024-T3 sheets by SPIF process and obtained the geometry of products. The processes parameters were vertical step, tool path, and lubrication type. And the rotational spindle speed, feed rate, wall angle, tool diameter, and coating of tool were constant. The dimensional accuracy were obtained used the 3D Laser Scanning method. The results are showed the spiral tool path was successful. Mariem Dakhli et al [9] studied the influenced of two geometries of the truncated cone on the geometrical accuracy. The sheet metal used was mild steel. The process parameters were thickness, vertical depth, feed rate, and spindle speed. The hemispherical tool with diameter (10 $\mathrm{mm}$ ) was used and the tool path type was spiral. Three-dimensional scanner was used to generate the profile of the manufactured surface and compared with the CAD profile. Zhengfang Li et al [10] presented the SPIF process for three types of the materials (1060 aluminum, Q235, and DC04 steel) and the influence of that on the geometrical accuracy. The height of specimens was different. The results showed that the strain strength coefficient and stepping rate are more effective factors on the geometrical accuracy. Zimeng Yao et al [11] studied the influence of vertical depth, thickness, wall angle, and tool diameter on the surface roughness, energy of deformation, and the geometrical accuracy in SPIF process. Cone parts were performed with the box-behnken design. The results indicated the optimum values of surface roughness $(0.97 \mu \mathrm{m})$, deformation energy $(1522.4 \mathrm{~J})$, and the geometrical error was $(1.939 \mathrm{~mm})$. The data were optimized with vertical depth $(0.5 \mathrm{~mm})$, thickness $(0.57 \mathrm{~mm})$, wall angle $\left(65^{\circ}\right)$, and tool diameter (16 mm).

\section{Experimental Work}

\subsection{Geometry Construction of Products}

The geometry of the formed products is pyramid shape with total depth of (35 mm) and with three different wall angle $\left(45^{\circ}, 50^{\circ}\right.$, and $55^{\circ}$ ) as shown in figure (3). The CAD model of the products illustrated in figure (3) is created by the following steps:

- Drawing the desired geometry of product by AutoCAD program and save the drawing in the extension format (dwg) for example (file name.dwg).

- Opening the saved drawing in the Solid Work (2013) program and then save the drawing in the extension format (part) for example (file name.prt).

- Opening the file name with the extension format (part) in the CAD/CAM package (Siemens UGS-NX9).

\subsection{Sheet Material}

The sheet material used in this work is pure Aluminum (Al 1050) with thickness of $(0.9 \mathrm{~mm})$. The initial dimensions of the blank were $(225 \times 225 \mathrm{~mm})$. The chemical composition test was carried out in "State Company for Inspection and Engineering Rehabilitation (SIER)" and the results of this test are illustrated in the table (1). And the tensile test was performed at "University of Technology-Production Engineering and Metallurgy to obtain the mechanical properties, the dimensions of the tensile specimen are taken according to ASTM EM8 and the results are illustrated in the table (2). 

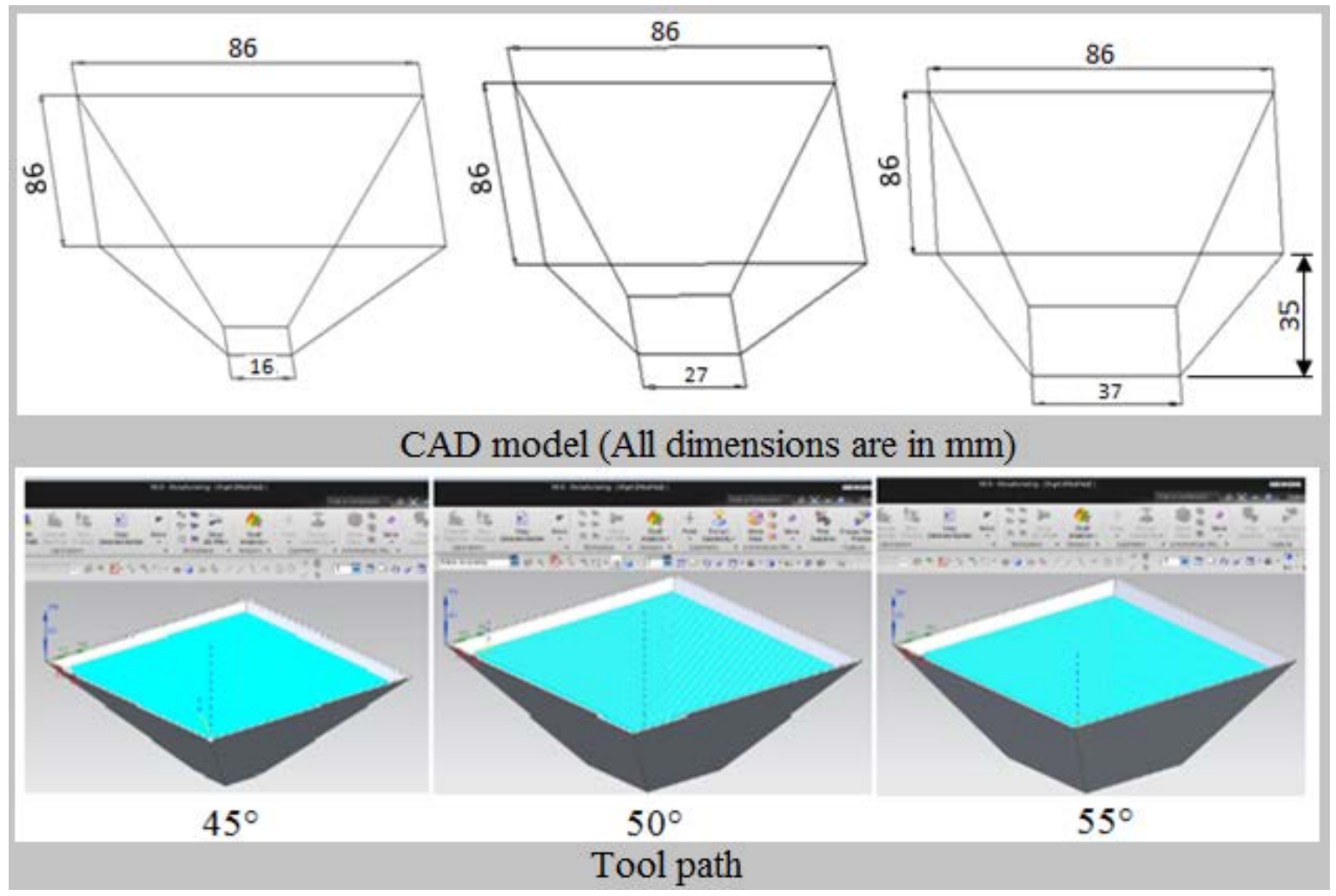

Figure 3: The CAD geometry and tool path of products.

Table 1: Chemical composition of the sheet material

\begin{tabular}{|c|c|c|c|c|c|c|c|c|c|c|}
\hline \multicolumn{2}{|c|}{ Material } & Al\% & Si\% & Fe\% & Cu\% & Mn\% & Mg\% & Cr\% & Ni\% & Zn\% \\
\hline & Measured & 99.5 & 0.142 & 0.315 & 0.013 & 0.013 & 0.001 & 0.001 & 0.003 & 0.006 \\
\cline { 2 - 10 } & ASTM \\
$\mathbf{1 0 5 0}$ & $\begin{array}{c}\text { Standard } \\
{[12]}\end{array}$ & $\leq 99.5$ & $\leq 0.25$ & $\leq 0.4$ & $\leq 0.05$ & $\leq 0.05$ & $\leq 0.05$ & $\leq 0.03$ & $\leq 0.03$ & $\leq 0.05$ \\
\hline
\end{tabular}

Table 2: Mechanical properties of the sheet material

\begin{tabular}{|c|c|c|c|c|c|c|}
\hline \multicolumn{2}{|c|}{ Material } & $\begin{array}{l}\text { Yield Stress } \\
\text { (MPa) }\end{array}$ & $\begin{array}{l}\text { Tensile } \\
\text { Strength }\end{array}$ & $\begin{array}{l}\text { Modulus of } \\
\text { Elasticity }\end{array}$ & $\begin{array}{c}\text { Elongation } \\
\%\end{array}$ & $\begin{array}{l}\text { Poisson's } \\
\text { Ratio }\end{array}$ \\
\hline \multirow[b]{2}{*}{$\begin{array}{c}\text { Al } \\
1050\end{array}$} & Measured & 71 & 86 & 72 & 4.1 & \multirow[b]{2}{*}{0.33} \\
\hline & $\begin{array}{c}\text { ASTM } \\
\text { Standard } \\
{[12]}\end{array}$ & $65-78$ & $80-100$ & 70-75 & $3.5-4.2$ & \\
\hline
\end{tabular}

\subsection{Forming Frame and Forming Tools}

Forming frame was utilized to fixate the blank on the CNC milling machine table. Forming frame is consisting of several components as shown in the figure (4). The Forming tools were used in this work were three different geometries with different sizes to study the effect of these tools on the dimensional accuracy. The first type was ball end with three diameters of $(8,10$, and 12) $\mathrm{mm}$. The second type was hemispherical shape with three diameters of $(8,10$, and 12$) \mathrm{mm}$. And the last type was flat end with round corner of different radius of $(3,4$, and 5$) \mathrm{mm}$. figure (5) was illustrated these tools.

\subsection{Design of Experimental}

In this work Taguchi's (L9) orthogonal array was used for three types of tools. The processes parameters and levels for the ball end, hemispherical and the flat with round corner tools are illustrated in the tables (3, 4, 5, 6 and 7).

\subsection{Forming Tests}

The SPIF processes of this work were performed utilized the 3-axis "C-Tek" CNC milling machine as shown in figure (6). The feed rate of $(800 \mathrm{~mm} / \mathrm{min})$ and vertical depth of $(1 / 3$ $\mathrm{mm}$ ) was used with all the tests. In this work, the lubrication type was used is PENNZOIL (SAE $5 \mathrm{~W}-30$ ), which is selected according to literatures 
researches. Figure (7) is shown the products, which was produced by the ball end, hemispherical, and the flat with round corner tools.

\section{Geometrical Accuracy Test}

In SPIF process, there is error between the product geometry and the desired geometry. This error is the distance between the designed profile and the experimental profile. Therefore, the measurement of the experimental profile is important. In this work, the experimental profile was measured by dimensional sensor which fixed on NC milling machine as shown in figure (8). The specifications of milling machine and MarTest device are illustrated in the tables (8 and 9).

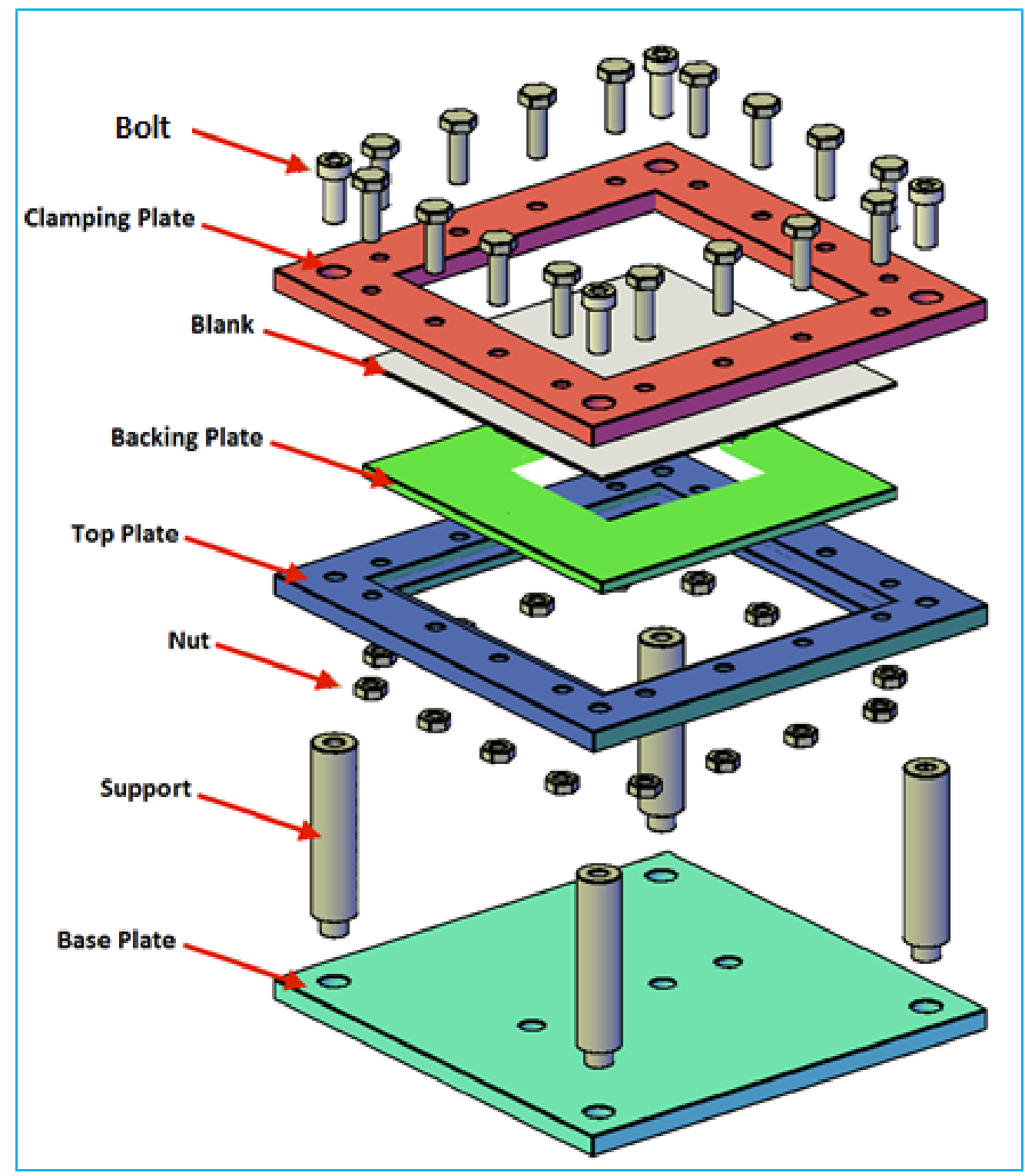

Figure 4: Assembly view of the forming frame. 


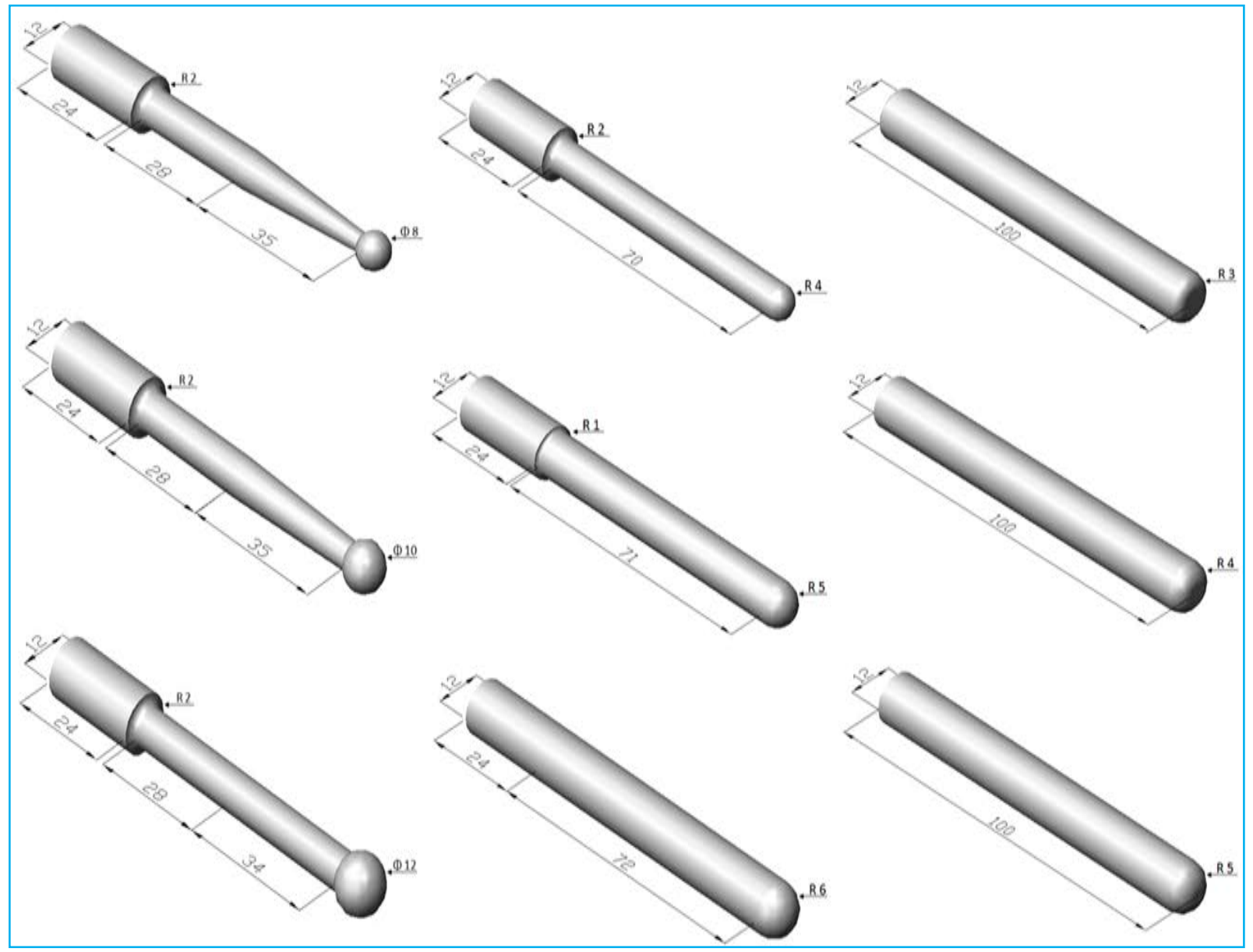

Figure 5: The tools used (All dimensions are in $\mathrm{mm}$ ).

Table 3: Forming parameters and their levels for ball end and hemispherical tools

\begin{tabular}{|c|c|c|c|c|}
\hline & Units & Level 1 & Level 2 & Level 3 \\
\hline Diameter & mm & $\mathbf{8}$ & $\mathbf{1 0}$ & 12 \\
\hline Angle & degree & $\mathbf{4 5}$ & 50 & 55 \\
\hline Spindle Speed & rpm & $\mathbf{0}$ & $\mathbf{4 0 0}$ & $\mathbf{8 0 0}$ \\
\hline
\end{tabular}

Table 4: Forming parameters and their levels for the flat with round corner tools

\begin{tabular}{|c|c|c|c|c|}
\hline & Units & Level 1 & Level 2 & Level 3 \\
\hline Radius & mm & 3 & 4 & 5 \\
\hline Angle & degree & 45 & 50 & 55 \\
\hline Spindle Speed & rpm & 0 & 400 & 800 \\
\hline
\end{tabular}

Table 5: Experimental layout using L9 orthogonal array and machining time for ball end tool

\begin{tabular}{|c|c|c|c|c|}
\hline \multirow{2}{*}{$\begin{array}{c}\text { Experimental } \\
\text { No. }\end{array}$} & \multicolumn{3}{|c|}{ Process Parameters } & \multirow{2}{*}{$\begin{array}{c}\text { Machining } \\
\text { Time (min) }\end{array}$} \\
\cline { 2 - 4 } & Diameter (mm) & $\begin{array}{c}\text { Angle } \\
\text { degree) }\end{array}$ & Spindle Speed (rpm) & 32.09 \\
\hline 1 & 1 & 1 & 1 & 34.16 \\
\hline 2 & 1 & 2 & 2 & 36.26 \\
\hline 3 & 1 & 3 & 3 & 31.01 \\
\hline 4 & 2 & 1 & 2 & 32.58 \\
\hline 5 & 2 & 2 & 3 & 34.59 \\
\hline 6 & 2 & 3 & 1 & 31.41 \\
\hline 7 & 3 & 1 & 3 & 33.32 \\
\hline 8 & 3 & 2 & 1 & \\
\hline 9 & 3 & 3 & 2 & \\
\hline
\end{tabular}


Table 6: Experimental layout using L9 orthogonal array and machining time for hemispherical tool

\begin{tabular}{|c|c|c|c|c|}
\hline \multirow{2}{*}{$\begin{array}{c}\text { Experimental } \\
\text { No. }\end{array}$} & \multicolumn{3}{|c|}{ Process Parameters } & \multirow{2}{*}{$\begin{array}{c}\text { Machining } \\
\text { Time (min) }\end{array}$} \\
\cline { 2 - 4 } & Diameter (mm) & $\begin{array}{c}\text { Angle } \\
\text { (degree) }\end{array}$ & Spindle Speed (rpm) & 32.09 \\
\hline 1 & 1 & 1 & 1 & 34.16 \\
\hline 2 & 1 & 2 & 2 & 36.26 \\
\hline 3 & 1 & 3 & 3 & 31.01 \\
\hline 4 & 2 & 1 & 2 & 32.58 \\
\hline 5 & 2 & 2 & 3 & 34.59 \\
\hline 6 & 2 & 3 & 1 & 31.41 \\
\hline 7 & 3 & 1 & 3 & 33.32 \\
\hline 8 & 3 & 2 & 1 & 2 \\
\hline 9 & 3 & 3 & 29.54 \\
\hline
\end{tabular}

Table 7: Experimental layout using L9 orthogonal array and machining time for the flat tool

\begin{tabular}{|c|c|c|c|c|}
\hline \multirow{2}{*}{$\begin{array}{c}\text { Experimental } \\
\text { No. }\end{array}$} & \multicolumn{3}{|c|}{ Process Parameters } & \multirow{2}{*}{$\begin{array}{c}\text { Machining } \\
\text { Time (min) }\end{array}$} \\
\cline { 2 - 4 } & Radius (mm) & $\begin{array}{c}\text { Angle } \\
\text { (degree) }\end{array}$ & Spindle Speed (rpm) & 28.11 \\
\hline 1 & 1 & 1 & 1 & 30.25 \\
\hline 2 & 1 & 2 & 2 & 32.46 \\
\hline 3 & 1 & 3 & 3 & 28.36 \\
\hline 4 & 2 & 1 & 2 & 30.44 \\
\hline 5 & 2 & 2 & 3 & 32.58 \\
\hline 6 & 2 & 3 & 1 & 3.02 \\
\hline 7 & 3 & 1 & 3 & 33.09 \\
\hline 8 & 3 & 2 & 1 & 2 \\
\hline 9 & 3 & 3 & 2 & \\
\hline
\end{tabular}

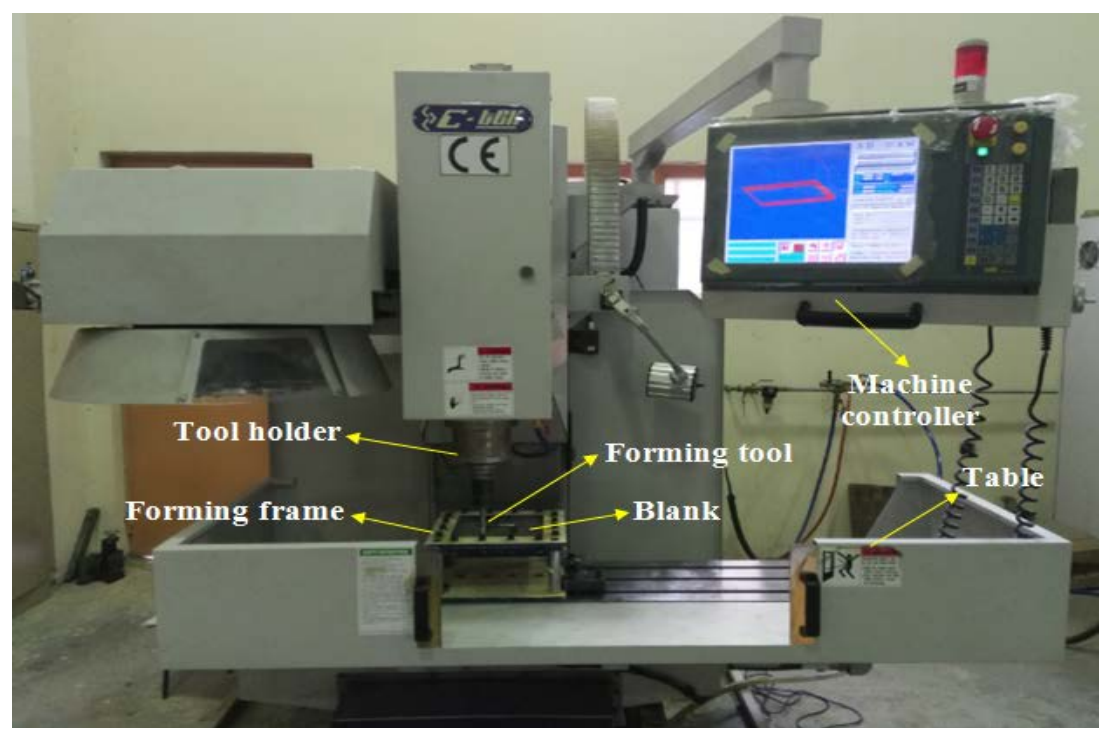

Figure 6: CNC milling machine utilized in experimental work. 


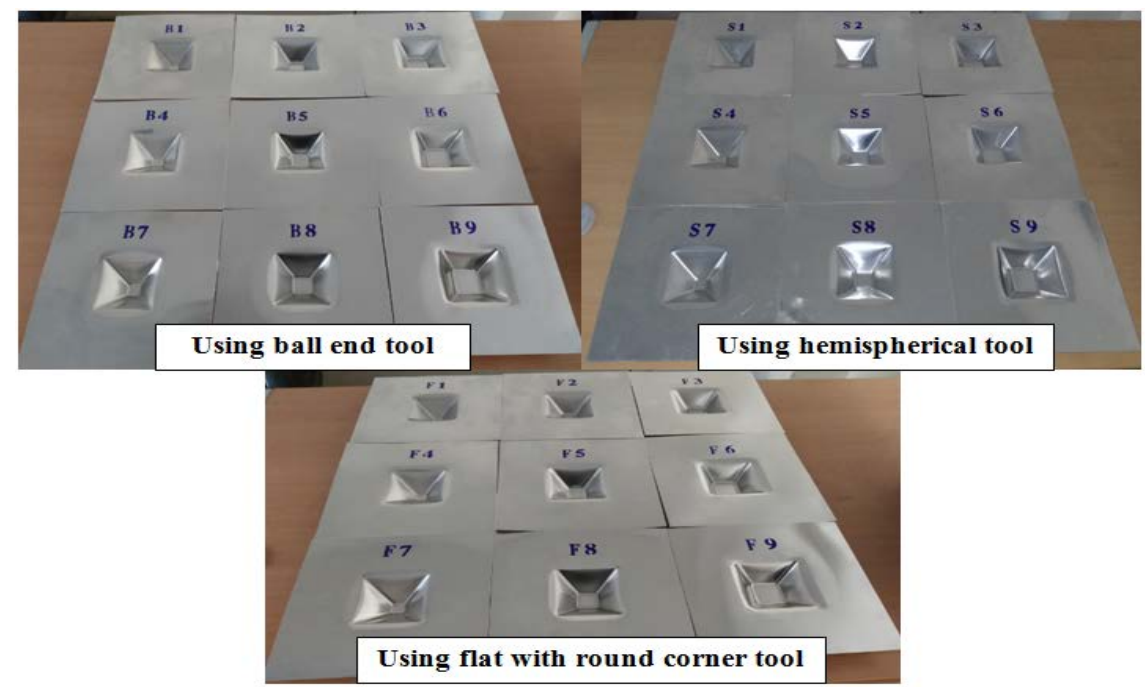

Figure 7: The products.

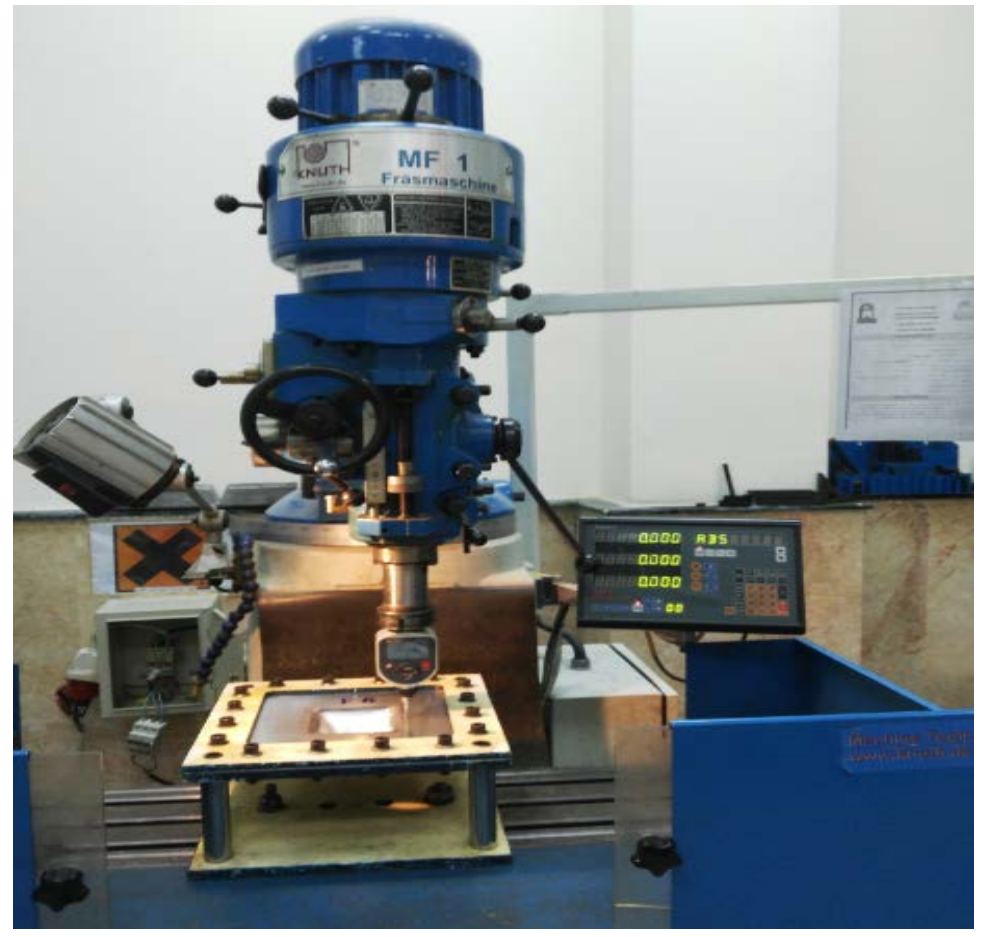

Figure 8: Dimensional accuracy measurement.

Table 8: Technical specifications of milling machine

\begin{tabular}{|c|c|}
\hline \multicolumn{2}{|c|}{ KNUCH MF1 Milling Machine } \\
\hline Table Set up Area & $(1800 \times 400) \mathbf{~ m m}$ \\
\hline Table Load Capacity & $\mathbf{1 0 0 0} \mathbf{~ K g}$ \\
\hline Travel $(\mathrm{X}, \mathrm{Y}, \mathrm{Z}$ ) Axis & $(\mathbf{1 2 5 0 , 5 4 0 , 4 7 0 )} \mathbf{~ m m}$ \\
\hline Weight & $(3 \times 2.54 \times 2.05) \mathbf{~ m}$ \\
\hline Oesolution & $3200 \mathrm{Kg}$ \\
\hline
\end{tabular}

Table 9: Dimensional measurement sensor specifications

\begin{tabular}{|c|c|}
\hline \multicolumn{2}{|c|}{ MarTest 802 EW Digital 3D-Touch Probe } \\
\hline Working Areas X, Y, Z Axis & $(-2$ To 4) mm \\
\hline Display Ranges & $+/-2 \mathrm{~mm}$ \\
\hline Repeatability at Zero Point, Unidirectional & $\pm 0.005 \mathrm{~mm}$ \\
\hline
\end{tabular}




\section{Results and Discussion}

The results of the dimensions accuracy which measured by utilized dimensional sensor measuring instrument as shown in figure (8). The table (10) is illustrated the dimensions measured for the ball end, hemispherical, and the flat with round corner tools. And the figure (9) presents the comparison between the CAD profiles with the measured profiles of the pyramid wall. The results indicated the rotational speed of the tool was increased, the heat generated in product was increased which leads to decrease the spring back and also when the wall angle was increased leads to increase in spring back. From figure (9) the best experimental run was $5^{\text {th }}$ with using ball end tool because it was less error between the CAD profile and the run profile.

Table 10: The dimensions measured for profiles

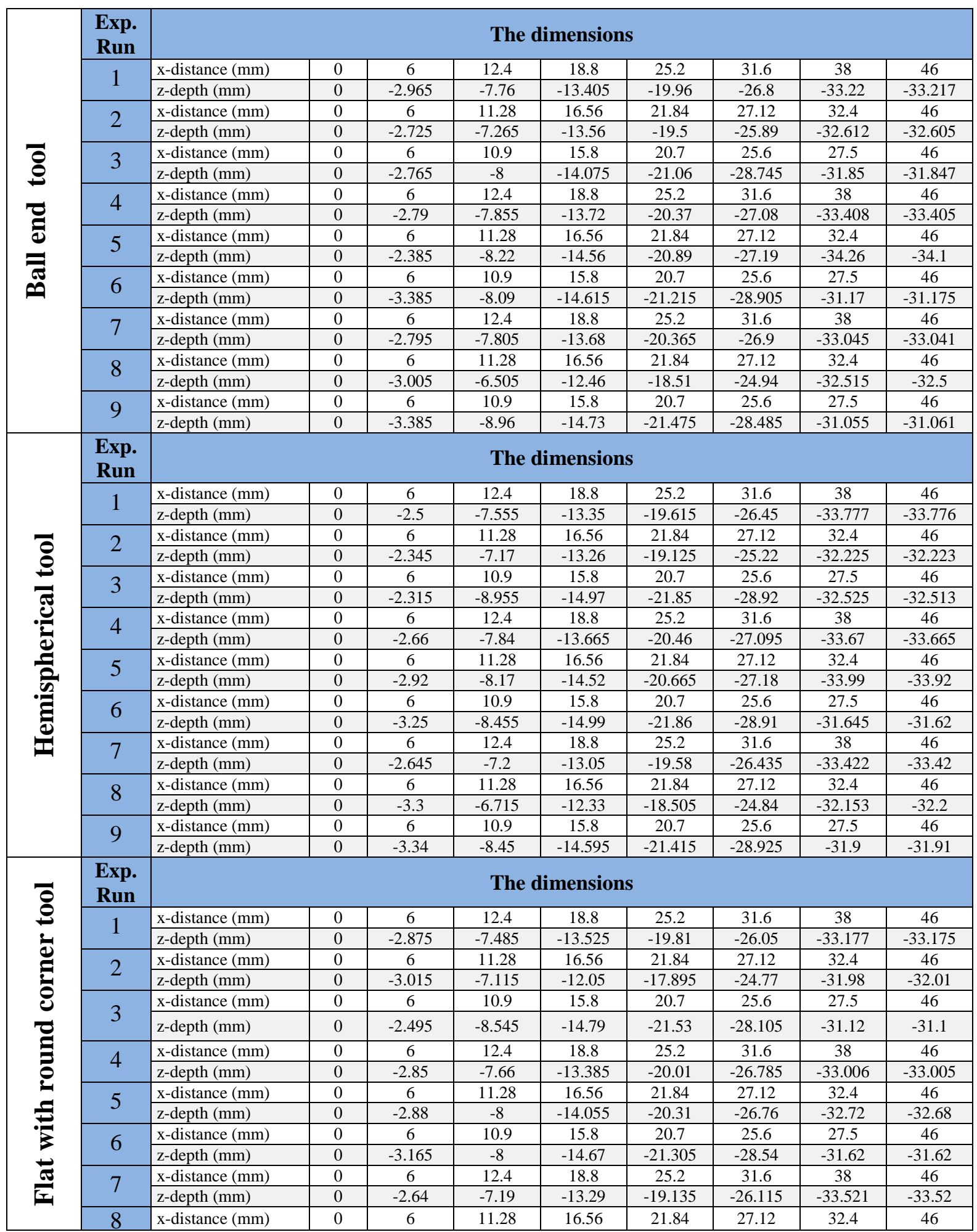




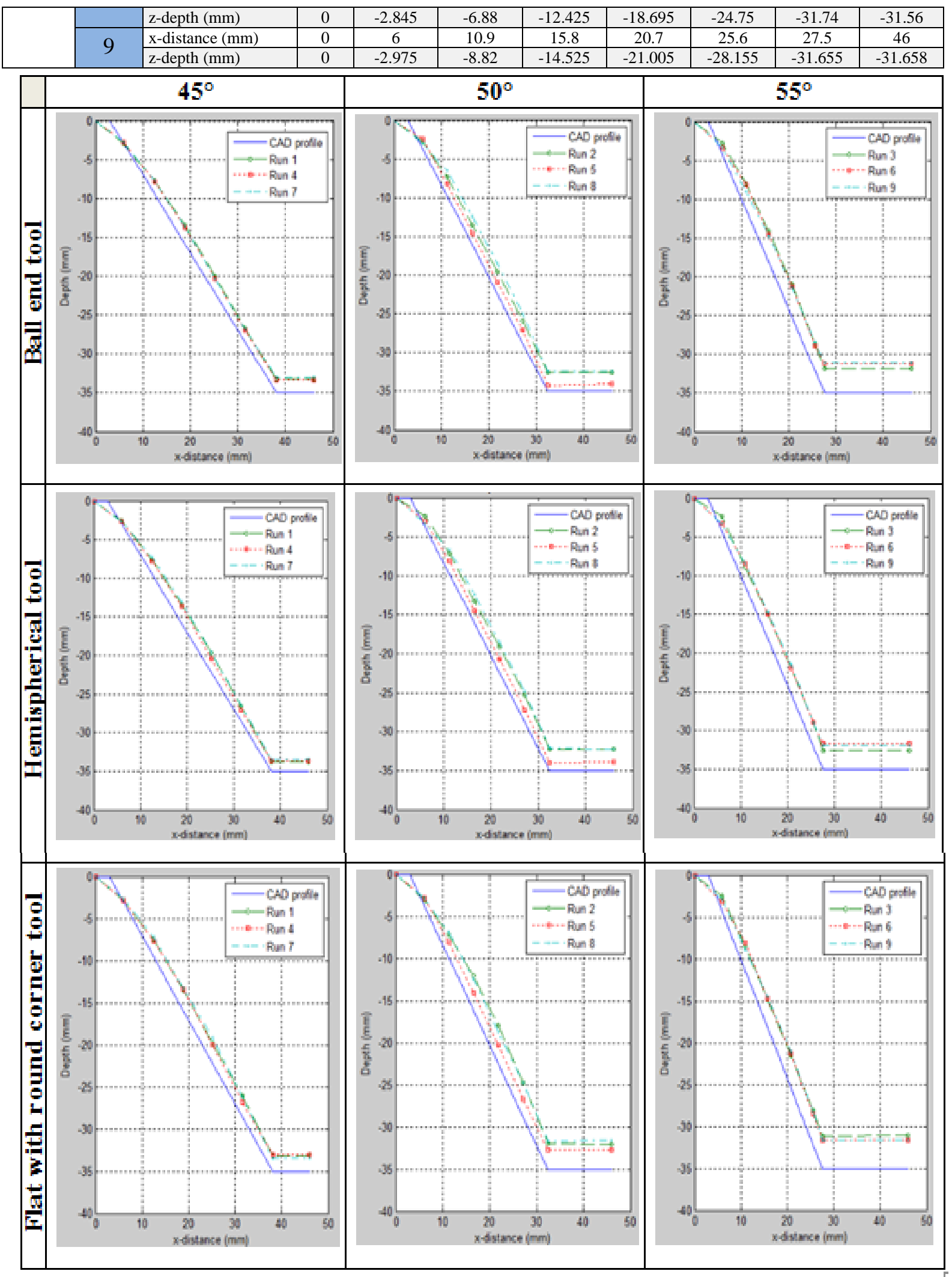

Figure 9: The comparison between CAD and measured profiles.

\section{Conclusions}

In this research, Al 1050 sheet were incremental formed under different forming tool geometry and their effects studies, the following conclusions were drawn from the study: 
1- The dimensional accuracy was acceptable when using the tool with small diameter and high speed of spindle.

2- The effect of tool diameter was more than the effect of rotational speed of tool on the dimensional accuracy.

3- The best profile obtained from measured was found with ball end tool at $2^{\text {nd }}$ level of tool diameter $(10 \mathrm{~mm})$ parameter and wall angle $\left(50^{\circ}\right)$ parameter and $3^{\text {rd }}$ level of rotational speed $(800 \mathrm{rpm})$ parameter.

\section{References}

[1] Rattanachan K. and Chungchoo Ch., "Formability in Single Point Incremental Forming of Dome Geometry", Asian International Journal of Science and Technology, Production and Manufacturing Engineering, Vol. 2, Pages 57-63, 2009.

[2] Baden A. S., "Optimization and Prediction of Process Parameters in SPIF that Affecting on Surface Quality Using Simulated Annealing Algorithm”, Al-Khwarizmi Engineering Journal, Vol. 12, No. 4, Pages 81-92, 2016.

[3] Ibrahim Aws K. and Hamdan Wisam K., "Application of Adaptive Neuro-Fuzzy Inference System for Prediction of Surface Roughness in Incremental Sheet Metal Forming Process", Engineering and Technology Journal, Vol. 33, Part A., No. 2, 2015.

[4] Abed A. Hamad, Bedan A. S., and Noori M. Faeq, "Study the Effect of Multilayer Single Point Incremental Forming on Tool Path Mark for AA1050 Bottom Plates", Engineering and Technology Journal, Vol. 35, Part A., No. 6, 2017.

[5] Bosetti Paolo and Bruschi Stefania, "Springback Evaluation of Parts Made by SinglePoint Incremental Sheet Forming”, Proceedings of the American Society of Mechanical Engineers, International Mechanical Engineering Congress \& Exposition, USA, 2011.
[6] Micari F., Ambrogio G., and Filice L., "Shape and Dimensional Accuracy in Single Point Incremental Forming: State of the Art and Future Trends”, Journal of Materials Processing Technology, Vol. 191, Issues 1-3, Pages 390395, 2007.

[7] Edwards William L., Grimm Tyler J., Rajai Ihab, and Roth John T., "Optimum Process Parameters for Springback Reduction of Single Point Incrementally Formed Polycarbonate”, Procedia Manufacturing, Vol. 10, Pages 329338, 2017.

[8] Bayram Halil and Köksal Nurullah Sinan, "Investigation of the Geometrical Accuracy and Thickness Distribution Using 3D Laser Scanning of AA2024-T3 Sheets Formed by SPIF", Materials and technology, Vol. 51, No. 1, Pages 111-116, 2017.

[9] Dakhli Mariem, Boulila Atef, and Tourki Zoubeir, "Effect of Generatrix Profile on SinglePoint Incremental Forming Parameters”, The International Journal of Advanced Manufacturing Technology, 2017.

[10] Li Zhengfang, Lu Shihong, Zhang Tao, Mao Zhixiang, and Zhang Chun, "Analysis of Geometrical Accuracy Based on Multistage Single Point Incremental Forming of a Straight Wall Box Part", The International Journal of Advanced Manufacturing Technology, 2017.

[11] Yao Zimeng, Li Yan, Yang Mingshun, Yuan Qilong, and Shi Pengtao, "Parameter Optimization for Deformation Energy and Forming Quality in Single Point Incremental Forming Process Using Response Surface Methodology”, Advances in Mechanical Engineering, Vol. 9, No. 7, Pages 1-15, 2017.

[12] ANNUAL BOOK OF ASTM STANDARDS, Library of Congress Catalog Card Number: 83-641658, ISBN 978-0-8031-8160-1 (set), ISBN 978-08031-8352-0 (volume), Printed in Baltimore, MD, U.S.A, 2010.

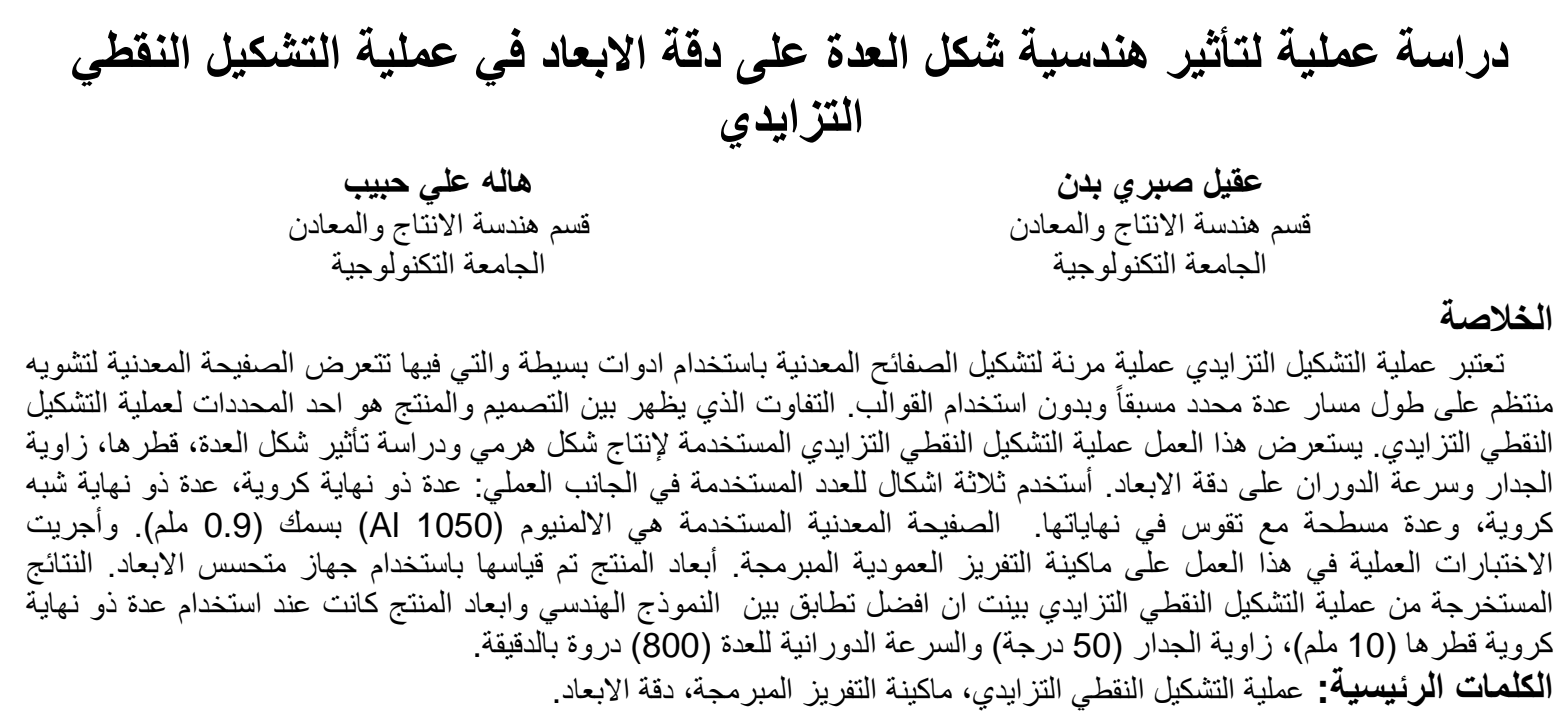

